\title{
Selection at the diazinon resistance locus in overwintering populations of Lucilia cuprina (the Australian sheep blowfly)
}

\author{
JOHN A. MCKENZIE \\ Department of Genetics, University of Melbourne, Parkville, VIC 3052, Australia
}

\begin{abstract}
In excess of 70 per cent mortality is observed during the overwintering stage of the life cycle of $L$. cuprina. The mortality is selective in the absence of a fitness modifier; phenotypes resistant to diazinon overwinter less successfully than susceptibles. In the presence of the modifier the overwintering success of all genotypes is similar. The effect is dominant. Laboratory and field experiments show that selection against resistant individuals increases with time in arrested development. The relevance of these results to the evolution of insecticide resistance is discussed.
\end{abstract}

Keywords: blowfly, diazinon resistance, ecological genetics, Lucilia cuprina, overwintering, selection.

\section{Introduction}

Studies on the evolution of insecticide resistance have allowed the impact of selection on the genetic structure of populations to be investigated in circumstances where the selective agent, the insecticide, is clearly defined (Roush \& McKenzie, 1987; Mallet, 1989; Roush \& Daly, 1990; Macnair, 1991; McKenzie \& Batterham, 1994).

Estimates of the relative success of resistant and susceptible phenotypes have been made for different stages of the life cycle in the presence and absence of the chemical (see Wood \& Bishop, 1981; Roush \& McKenzie, 1987; Mallet, 1989; Roush \& Daly, 1990; Denholm \& Rowland, 1992; McKenzie \& Batterham, 1994, for reviews).

In general, susceptible individuals are at a selective advantage, or disadvantage, in the absence, or presence, of the pesticide, respectively. In the former instance the relative difference between susceptible and resistant phenotypes may not be large (Roush \& McKenzie, 1987) although the overwintering phase of the life cycle has largely been ignored in these comparisons. Given that mortality may be significant during this period the potential for selection exists; however, the few studies conducted give equivocal results (Roush \& Hoy, 1981; Daly \& Fitt, 1990; McKenzie, 1990).

The studies of Roush \& Hoy (1981) and Daly \& Fitt (1990) suggest that any selection against resistant individuals is minor. For dieldrin resistance in the Australian sheep blowfly, Lucilia cuprina, selection against resistant individuals during overwintering is dominant and severe (McKenzie, 1990). The impact of selection during this period can have a significant influence on the management of resistance as populations increase during spring (Taylor \& Georghiou, 1979; Denholm et al., 1985; Daly \& Fitt, 1990), therefore it is important to increase the database provided by the three previous studies. The diazinon-resistance system in $L$. cuprina provides an opportunity.

In natural populations of $L$. cuprina resistance to diazinon is controlled by substitution of the $R_{l A}$ for the + allele at the Rop-1 locus on chromosome IV (McKenzie, 1993). Selection for resistance was recessive (McKenzie \& Whitten, 1982). Continued use of the insecticide, after resistance was widespread, selected a modifier that enhanced the relative fitness of resistant phenotypes (McKenzie et al., 1982). Thus, after modification, susceptible and resistant phenotypes have comparable fitness in the absence of the insecticide. The effect of the modifier is dominant and controlled by a single gene on chromosome III (McKenzie \& Game, 1987; McKenzie, 1993).

L. cuprina is active in southeastern Australian populations from October to May (Foster et al., 1975). Larvae develop on sheep, enter a wandering phase, drop to the ground and burrow into the soil to pupate. Larvae entering the ground in May overwinter as prepupae, adults emerging in October. Survivorship during the overwintering period may be less than 10 per cent. Soil temperature is an important variable in arresting development (Foster et al., 1975; Dallwitz \& Wardhaugh, 1984; McKenzie, 1990). 
The diazinon-resistance system in L. cuprina is therefore sufficiently ecologically and genetically defined to test the relative viabilities of susceptible and resistant phenotypes during overwintering. The influence of the modifier during this stage of the life cycle is also of considerable evolutionary interest.

\section{Materials and methods}

\section{Strains and crosses}

The strains used were a diazinon-resistant strain homozygous for the $R_{l A}$ allele of the Rop- 1 locus $\left\langle R_{I A}\right|$ $R_{I A}$ ), a reference susceptible strain (SWT) homozygous for the + allele at Rop- $I$ and four strains homozygous at the modifier and Rop-1 loci $(M / M$; $R_{I A} / R_{I A}, M / M ;+1+,+1+; R_{I A} / R_{I A}$ and $+1+;+1$ $+)$. The $R_{1 \mathrm{~A}} / \mathrm{R}_{1 \mathrm{~A}}$ and SWT strains were both $+/+$ at the modifier locus.

In the 1986-1988 experiments $R_{I A} / R_{I A}$ and SWT were crossed and $F_{2}$ larvae allowed to develop for 4 days at $27 \pm 1^{\circ} \mathrm{C}$ on standard laboratory medium. Wandering larvae were then collected (McKenzie, 1990).

The four modifier/Rop-1 strains were crossed in combinations to generate the nine possible modifier and diazinon-resistance genotypes. Larvae of these genotypes were collected for experiments during 1991-1993, after development as described above.

\section{6-1988 experiments}

Collection of wandering larvae and establishment of field trials and laboratory controls. The procedure followed that of McKenzie (1990). Samples of 100 wandering larvae were collected and added to soil in containers that were placed in the ground or held in the laboratory at $27 \pm 1^{\circ} \mathrm{C}$. Five trials were established for each field experiment and laboratory control which were conducted to extend beyond periods of blowfly activity (October-June; McKenzie, 1990).

In May 1987 six extra containers were placed in the ground, and an extra control was established at $27 \pm 1^{\circ} \mathrm{C}$. One field container was removed after 2 months in the ground and returned to the laboratory at $27 \pm 1^{\circ} \mathrm{C}$ to allow completion of blowfly development. This procedure was repeated with two and three containers after 3 and 4 months in the ground.

Numbers and resistance status of emerging adults. Emerging flies were collected (McKenzie, 1990), aged for 2 days at $27 \pm 1^{\circ} \mathrm{C}$ and then treated with doses of diazinon dissolved in deodorized kerosene; $0.5 \mu \mathrm{L}$ at 0.01 per cent $(v / v)$ to distinguish between $+/+$ and
$R_{I A} /+$, and thence 0.025 per cent $(\mathrm{v} / \mathrm{v})$ to distinguish between $R_{I A} /+$ and $R_{I A} / R_{I A}$ (McKenzie et al., 1980). The number of flies emerging from each trial was recorded.

Temperature trials in the laboratory. Temperatures of less than $10^{\circ} \mathrm{C}$ inhibit pupation in wandering larvae (Foster et al., 1975). During winter, temperatures in the soil in the containers fluctuated about $8^{\circ} \mathrm{C}$ (McKenzie, 1990); thus the laboratory experiment was conducted at this temperature.

Samples of 100 wandering larvae were collected and containers placed at $8 \pm 1^{\circ} \mathrm{C}$, a control being established at $27 \pm 1{ }^{\circ} \mathrm{C}$. After 3,5 and 9 weeks at the experimental temperature the containers were transferred to $27 \pm 1^{\circ} \mathrm{C}$ to allow completion of blowfly development. The numbers and resistance status of emerging adults were determined as described above. Four trials were conducted.

\section{1-1993 experiments}

The methods followed the 1986-1988 field series. At approximately monthly intervals during periods of blowfly activity from October 1991 to June 1993 samples of wandering larvae of each of the nine modifier and Rop- 1 genotypes were collected in containers. These were held as controls in the laboratory sample and two field samples were established for each genotype.

In May and June of 1992 and 1993 five extra samples of each genotype were collected in containers. One container was placed at $27 \pm 1^{\circ} \mathrm{C}$, the other four below ground. At monthly intervals, for 4 months, one field container of each genotype was returned to $27 \pm 1^{\circ} \mathrm{C}$ in the laboratory.

The number of adults emerging was recorded for all samples.

\section{Results}

\section{6-1988 experiments}

Field trials and laboratory controls. The results of the laboratory controls were consistent over time (Fig. 1). The proportion of wandering larvae reaching adulthood was in the range of 78-96 per cent with no trend apparent with time of the year. $R_{l A}$ allele frequencies fluctuated $(0.43-0.55)$ about the expected value of 0.50 in an $\mathrm{F}_{2}$ population.

The data of the field trials were more variable (Fig. 1). Significant mortality may occur at any time of the year. However, importantly with respect to the Rop-1 locus, this mortality is selective during the overwinter- 
Fig. 1 The proportion of adults emerging after development from the wandering larvae stage of the life cycle and the frequency of the $R_{I A}$ allele in these blowflies for laboratory controls $(\diamond)$ and field experiments ( $)$ established in the months shown during 1986-1988. The data are pooled over five trials.
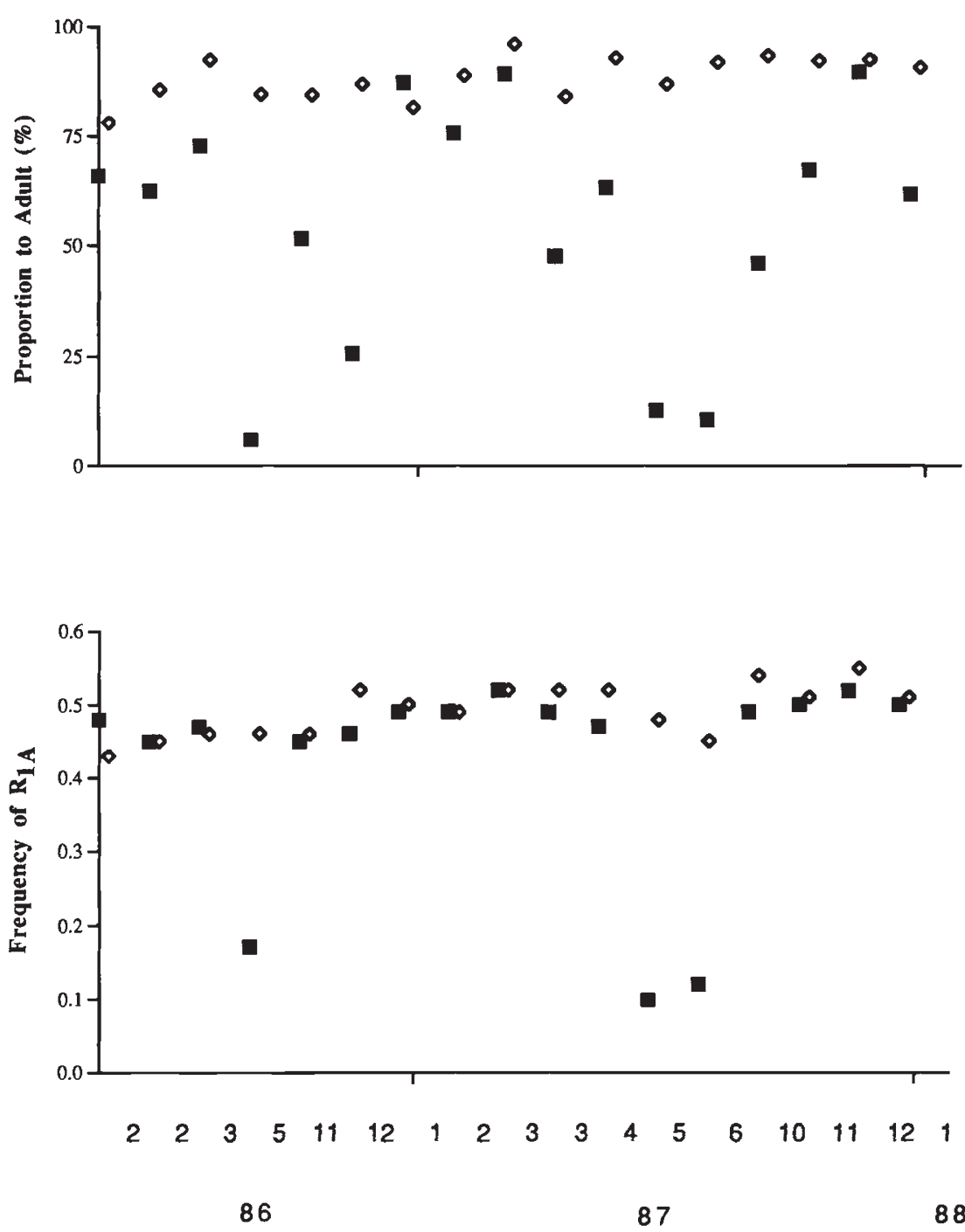

ing period. The overall mortality of pre-pupae is greater than 85 per cent and the frequency of the $R_{I A}$ allele is less than $0.2(0.10-0.17)$ in blowflies emerging after overwintering (Fig. 1). In continuously developing populations any selection against resistant individuals is relatively minor. For example in December 1986, when there was significant mortality, the frequency of the $R_{I A}$ allele, 0.46 , was within the range of controls. This is the general observation for other than overwintering populations (Fig. 1).

The sequential study, in which containers were removed from the ground at monthly intervals during overwintering, supports these observations. There is an inverse relationship between the proportion of adults emerging and time spent in the ground by pre-pupae (Fig. 2). A similar relationship is observed for the fre- quency of the $R_{1 A}$ allele in emerging flies; there is a consistent decrease with time in the overwintering phase (Fig. 2).

Laboratory trials at $8^{\circ} \mathrm{C}$. The proportion of wandering $\mathrm{F}_{2}$ larvae that developed to adults and the frequency of the $R_{I A}$ allele in these blowflies decreased with the time the samples were held at $8^{\circ} \mathrm{C}$. Similar patterns were observed in each of the four trials (Table 1).

\section{1-1993 experiments}

The nine genotypes have been pooled into three classes, $M / M ;-/-, M /+;-/-$ and $+/+;-/-$ for ease of presentation (Fig. 3). For all comparisons the 


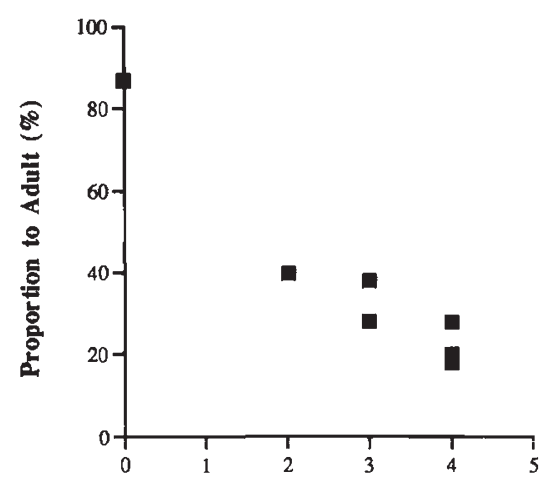

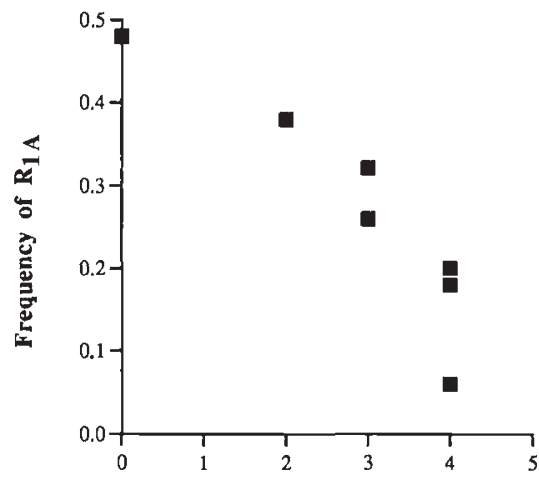

Months
Fig. 2 The proportion of wandering larvae that develop to adults and the $R_{I A}$ allele frequency in these blowflies in populations held in the ground for $0-4$ months during the overwintering phase.
Table 1 The number of flies emerging (a), from initial samples of 100 wandering larvae, in each of four trials after periods of $0-9$ weeks at $8^{\circ} \mathrm{C}$ before transfer to $27^{\circ} \mathrm{C}$. $R_{I A}$ allelic frequency is provided for each sample $(\mathrm{b})$

\begin{tabular}{cccccc}
\hline & \multicolumn{5}{c}{ Weeks at $8^{\circ} \mathrm{C}$} \\
\cline { 3 - 6 } Trial & 0 & 3 & 5 & 9 \\
\hline & (a) & 96 & 56 & 47 & 4 \\
1 & (a) & 0.48 & 0.41 & 0.38 & 0.13 \\
& (b) & 88 & 46 & 40 & 0 \\
2 & (a) & 88 & 0.40 & 0.35 & - \\
& (b) & 0.47 & 43 & 30 & 0 \\
3 & (a) & 88 & 45 & 0.35 & - \\
& (b) & 0.49 & 0.41 & 23 & 3 \\
4 & (a) & 72 & 40 & 0.23 & 0.17 \\
& (b) & 0.49 & 0.39 & 0.23 \\
\hline
\end{tabular}

results of the laboratory trials are similar irrespective of the time of year. The proportion of adults emerging is in the range 82-100 per cent for all three classes, and the $R_{I A}$ allele frequencies fluctuate about 0.50 in each case (Fig. 3). The results are similar to those observed in the 1986-1988 experiments (Fig. 1).

The comparison extends to the field data with respect to the proportion of adults emerging. During the overwintering phase of 1992 and 1993 mortality is significantly greater than during other times of the year. Interestingly, in each of these four trials the proportion of adults emerging from the $+1+;-1-$ class is lowest. In this class alone the frequency of the $R_{1 A}$ allele decreases, relative to controls and non-overwintering populations, in adults emerging in October (Fig. 3). This class, without the modifier, is genetically most comparable to the $F_{2}$ genotypes of the 1986-1988 experiments (Fig. 1). Significant mortality, without selection against the $R_{I A}$ allele, is observed for $M / M$; $-/-$ and $M /+;-/-$ genotypic samples placed in the ground in May and June, the overwintering samples (Fig. 3).

These results are confirmed by the experiments in which samples are sequentially removed during the overwintering period. In 1992 and 1993 there is a consistent decrease in the proportion of adults of all genotypes emerging with increasing time of developmental arrest. A corresponding decrease in the frequency of the $R_{I A}$ allele is observed only for the $+1+;-1-$ class (Fig. 4).

\section{Discussion}

In previous overwintering experiments using $\mathrm{F}_{2}$ larvae of an original cross between pure-breeding susceptible and dieldrin-resistant $(R d l / R d l)$ strains, the proportion of the overwintering population that reached the adult stage was low (2.8-6 per cent) compared to those of continuously developing populations $(52.8-80$ per cent). The frequencies of the $R d l$ allele in adults emerging from the overwintering populations $(0.09-0.15)$ were significantly lower than at other times $(0.44-0.52)$ when the values approximated those of laboratory controls (0.43-0.53) (McKenzie, 1990). The results from the 1986-1988 experiments for diazinon-resistance genotypes are similar to those observed for dieldrinresistant populations, although the mortality observed in continuously developing populations was greater on occasions.

In continuously developing field populations the proportion reaching the adult stage ranged from 25.6 to 89.2 per cent. There was little evidence of selection against $R_{I A}$ at this stage as frequencies fluctuated $(0.45-0.52)$ about the expected value of 0.5 and in the range of values observed in the controls $(0.43-0.55)$ (Fig. 1). After the overwintering period the proportion of pre-pupae emerging as adults in October is small (5.9-12.7 per cent). The frequency of the $R_{I A}$ allele in these blowflies $(0.10-0.17)$ indicates considerable 
Fig. 3 The proportion of adults emerging after development from wandering larvae and the frequency of the $R_{I A}$ allele in these blowflies. The results are pooled for $M / M ; R_{I A} / R_{I A}, M / M ; R_{I A} /$ + and $M / M ;+1+(\square$, laboratory data; - field data), $M /+; R_{I A}\left|R_{I A}, M\right|+$; $R_{I A} /+$ and $M I+;+1+(\diamond ; \bullet)$ and +1 $+; R_{I A} / R_{I A},+\mid+; R_{I A} /+$ and $+\mid+$; $+/+(0 ; \bullet)$. The trials were started in the months shown during 1991-1993.
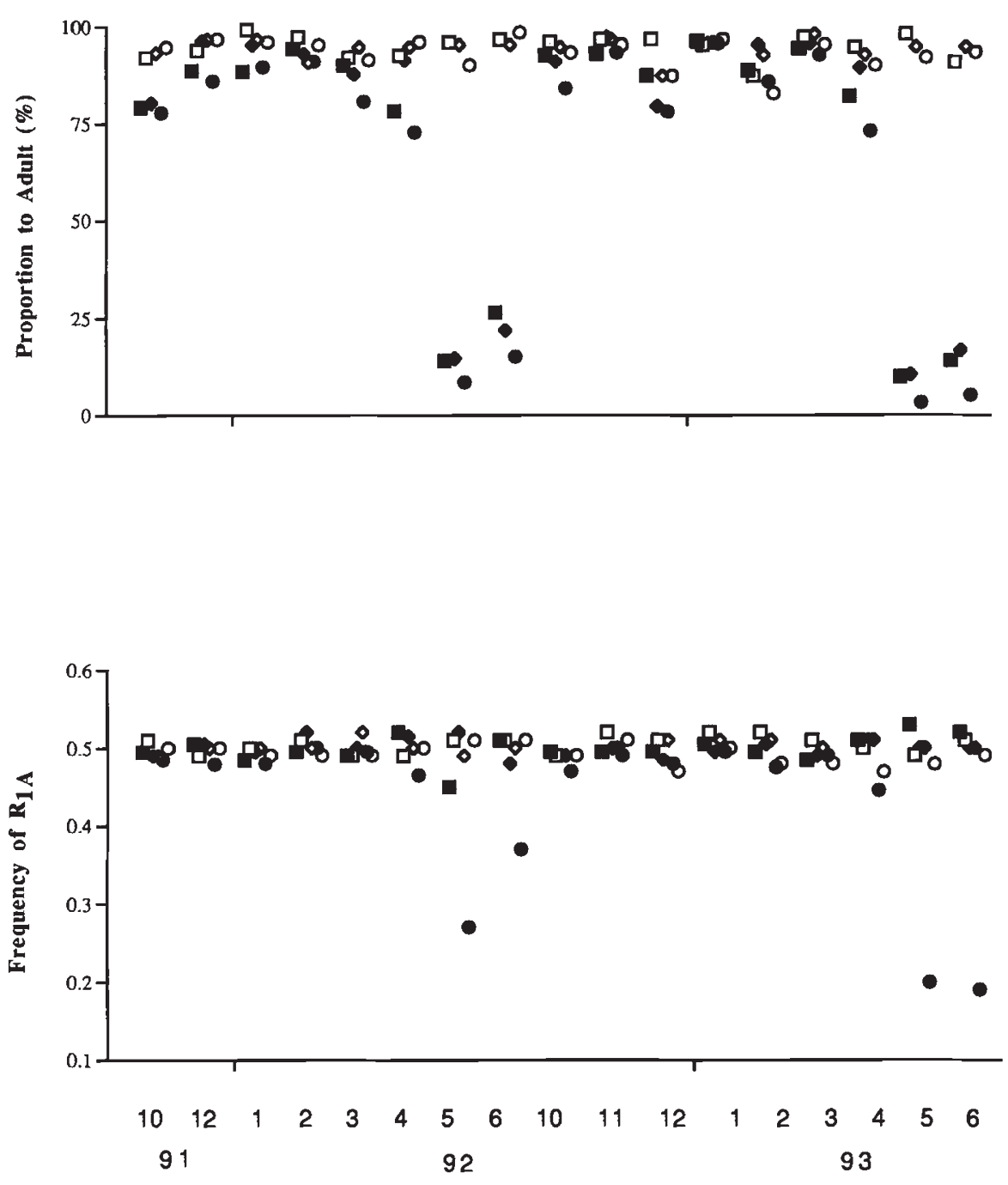

selection against resistant individuals at this stage (Fig. 1).

In the sequential experiments, in which pre-pupae were removed from the ground at regular intervals during overwintering, there was a consistent decline in the proportion reaching the adult stage and in the frequency of $R_{I A}$ in these populations with increasing time in the ground (Fig. 2). Laboratory experiments in which pre-pupae were held in arrested development at $8^{\circ} \mathrm{C}$ for up to 9 weeks showed similar trends (Table 1 ). Comparable observations had been made for dieldrinresistant genotypes (McKenzie, 1990).

Dieldrin resistance in Lucilia cuprina is likely to involve alteration of a GABA receptor/chloride channel target site (Soderlund \& Bloomquist, 1990; ffrench-Constant et al., 1993; McKenzie \& Batterham, 1994). Resistance to diazinon involves an altered carboxylesterase (Hughes \& Devonshire, 1982). The independence of the biochemical mechanisms between the two systems suggests that the selective effect during developmental arrest may involve a general, rather than a specific, 'cost' (Maynard Smith et al., 1985). This is supported by the general mortalities observed for resistant and susceptible phenotypes during the overwintering phase (Figs 1-4) and by the disruptive effects of the resistant alleles when resistance first evolves (Clarke \& McKenzie, 1987).

Developmental disruption may be measured by departures from symmetry of a normally bilaterally symmetrical organism (Palmer \& Strobeck, 1986; Graham, 1992; Parsons, 1992). Dieldrin, diazinon and malathion-resistant $L$. cuprina show elevated levels of asymmetry and reduced fitness relative to susceptibles. In the latter two cases a fitness/asymmetry modifier has evolved ameliorating these effects (Clarke \& McKenzie, 1987; McKenzie \& Clarke, 1988; 
1992
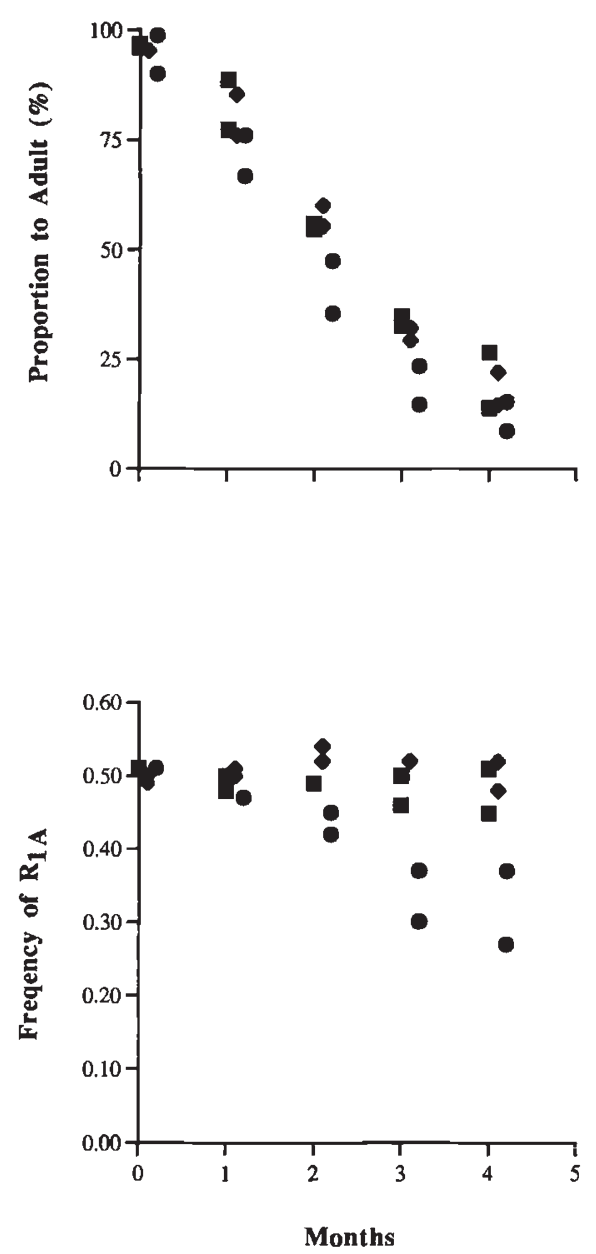

1993
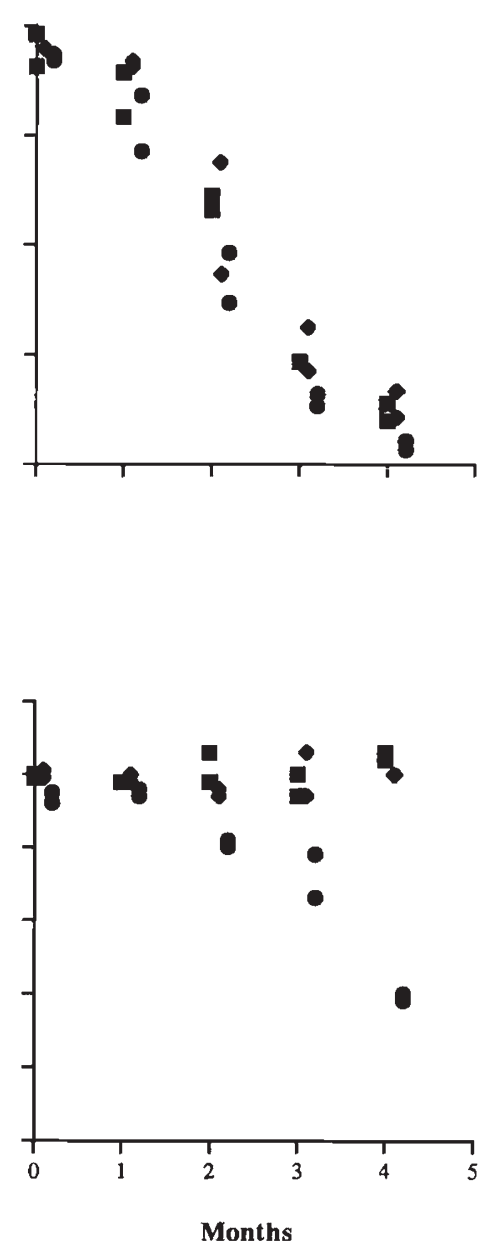

Fig. 4 The proportion of wandering larvae that develop to adults and the $R_{I A}$ allele frequency in those blowflies in $M / M ;-1-(\square), M /+;-1-(\bullet)$ and $+1+;-1-(\bullet)$ genotypes after $0-4$ months in the overwintering phase. Experiments were commenced in May and June of 1992 and 1993.
McKenzie \& O'Farrell, 1993). The selective cost of being resistant during the overwintering period is also influenced by the modifier. There is a clear distinction between the overwintering success of $M /-; R_{I A} /-$ and $+\mid+; R_{I A} /-$ individuals (Figs 3 and 4 ). This is particularly emphasized as $M /-;+/+(10-24$ per cent $)$ and $+1+;+1+(6-22$ per cent $)$ have comparable emergence percentages across trials and years.

The influence of the modifier on all stages of the life cycle has significant consequences for the maintenance of the $R_{I A}$ allele in natural populations of $L$. cuprina. Even if diazinon usage was discontinued for blowfly control this allele would be expected to persist at its current high frequency (McKenzie, 1993). This expectation provides a striking contrast to the observed rapid decline in the frequency of the $R d l$ allele (McKenzie, 1990), a situation expected if diazinon had been withdrawn in the early 1970 s, after resistance had evolved but before the modifier had been selected
(McKenzie et al., 1982). The co adaptation of the resistant allele is therefore of considerable evolutionary consequence. However, while commonly expected (Abedi \& Brown, 1960), the phenomenon has been seldom observed, presumably because an insecticide has not been consistently used after resistance has developed (Roush \& McKenzie, 1987; McKenzie, 1993). An evolutionary parallel may exist in recent observations of rats resistant to the anticoagulant poison warfarin. Their relative fitness is enhanced, relative to susceptibles, in the absence of pesticide, after persistent warfarin use post-resistance development (Smith et al., 1993). In this context, resistance studies may provide an opportunity for an experimental investigation of co adaptation under defined ecological conditions.

Bishop (1973) strongly made the point that evolutionary studies are most effective when the population biology of the organism is studied. This framework 
assumes that all stages of the life cycle must be considered. With respect to the evolution of insecticide resistance, this and previous studies indicate that while the impact of selection during the overwintering phase may vary (Roush \& Hoy, 1981; Daly \& Fitt, 1990; Mckenzie, 1990) the overwintering stage of the life cycle should not be ignored.

\section{Acknowledgements}

Kate Anderson, Melinda Christopherson, Jenny Fegent and Janet and Beverly Yen are thanked for excellent technical assistance at various stages of the work. Janet Yen's efforts with the figures are particularly appreciated. Financial support was provided by the Wool Research and Development Corporation and the Australian Research Council.

\section{References}

ABEDI, Z. H. AND BRown, A. W. A. 1960. Development and reversion of DDT-resistance in Aedes aegypti. Can. J. Genet. Cytol., 2, 252-261.

BISHOP, J. A. 1973. The proper study of populations. In: Geier, P. W., Clark, L. R., Anderson, D. J. and Nix, H. A. (eds) Insects: Studies in Population Management, pp. 52-68. Ecological Society of Australia, Canberra.

ClARKE, G. M. AND McKENZIE, J. A. 1987. Developmental stability of insecticide resistant phenotypes in blowfly, a result of canalizing natural selection. Nature, 325, 345-346.

DALlWITZ, R. AND WARDHAUGH, K. G. 1984. Overwintering of pre-pupae of Lucilia cuprina (Diptera: Calliphoridae) in the Canberra region. J. Aust. Entomol. Soc., 23, 307-312.

DALY, J. C. AND FITT, G. P. 1990. Resistance frequencies in overwintering pupae and the spring generation of Helicoverpa armigera (Hübner) (Lepidoptera: Noctuidae) in northern New South Wales, Australia: selective mortality and gene flow. J. Econ. Entomol., 83, 1682-1688.

DENHOLM, I. AND ROWLAND, M. W. 1992. Tactics for managing pesticide resistance in arthropods. Ann. Rev. Entomol., 37, 91-112.

DENHOLM, I., SAWICKI, R. M. AND FARNhAM, A. W. 1985. Factors affecting resistance to insecticides in house-flies, Musca domestica L. (Diptera: Muscidae). IV. The population biology of flies on farms in south-eastern England and its implications for the management of resistance. Bull. Entomol. Res., 75, 143-158.

FFRENCH-CONSTANT, R. H., ROCHELEAU, T. A., STEICHEN, J. C. AND Chalmers, A. E. 1993. A point mutation in a Drosophila GABA receptor confers insecticide resistance. Nature, 363, 449-451.

FOSTER, G. G., KITCHING, R. L., VOGT, W. G. AND WHITTEN, M. J. 1975. Sheep blowfly and its control in the pastoral ecosystem of Australia. Proc. Ecol. Soc. Aust., 9, 213-229.

GRAHAM, J. H. 1992. Genomic co-adaptation and developmental stability in hybrid zones. Acta Zool. Fennica, 191, 121-131.
HUGHES, P. B. AND DEVONSHIRE, A. L. 1982. The biochemical basis of resistance to organophosphorus insecticides in the sheep blowfly Lucilia cuprina. Pestic. Biochem. Physiol., 18, 289-297.

MACNAIR, M. R. 1991. Why the evolution of resistance to anthropogenic toxins normally involves major gene changes: the limits to natural selection. Genetica, 84, 213-219.

MALLET, J. 1989. The evolution of insecticide resistance: have the insects won? Trends Ecol. Evol., 4, 336-340.

MAYNARD SMITH, J., BURIAN, R., KAUFFMAN, S., ALBERCH, P., CAMPBELL, J., GOODWIN, B., LANDE, R., RAUP, D. AND WOLPERT, L. 1985. Developmental constraints and evolution. Quart. Rev. Biol., 60, 266-287.

McKENZIE, J. A. 1990. Selection at the dieldrin resistance locus in overwintering populations of Lucilia cuprina (Wiedemann). Aust. J. Zool., 38, 493-501.

McKENZIE, J. A. 1993. Measuring fitness and intergenic interactions: the evolution of resistance to diazinon in Lucilia cuprina. Genetica, 90, 227-237.

McKenZIE, J. A. AND BATTERHAM, P. 1994. The genetic, molecular and phenotypic consequences of selection for insecticide resistance. Trends Ecol. Evol., 9, 166-169.

McKENZIE, J. A. AND ClARKE, G. M. 1988. Diazinon resistance, fluctuating asymmetry and fitness in the Australian sheep blowfly, Lucilia cuprina. Genetics, 120, 213-220.

McKENZIE, J. A. AND O'FARRELL, K. 1993. Modification of developmental instability and fitness: malathion-resistance in the Australian sheep blowfly, Lucilia cuprina. Genetica, 89, 67-76.

McKENZIE, J. A. AND GAME. A. Y. 1987. Diazinon resistance in Lucilia cuprina: mapping of a fitness modifier. Heredity, 59, 371-381.

McKenZIE, J. A. AND WHITTEN, M. J. 1982. Selection for insecticide resistance in the Australian sheep blowfly, Lucilia cuprina. Experientia, 38, 84-85.

McKENZIE, J. A., DEARN, M. J. AND WhitTEN, M. J. 1980. Genetic basis of resistance to diazinon in Victorian populations of the Australian sheep blowfly, Lucilia cuprina. Aust. J. Biol. Sci., 33, 85-95.

McKenZiE, J. A., WhiTTEN, M. J. AND ADENA, M. A. 1982. The effect of genetic background on the fitness of diazinon resistance genotypes of the Australian sheep blowfly, Lucilia cuprina. Heredity, 49, 1-9.

PALMER, A. R. AND STROBECK, C. 1986. Fluctuating asymmetry: measurement, analysis, patterns. Ann. Rev. Ecol. Syst., 17, 391-421.

PARSONS, P. A. 1992. Fluctuating asymmetry: a biological monitor of environmental and genomic stress. Heredity, 68, $361-364$.

ROUSH, R. T. AND DALY, J. C. 1990. The role of population genetics in resistance research and management. In: Roush, R. T. and Tabashnik, B. E. (eds) Pesticide Resistance in Arthropods, pp. 97-152. Chapman and Hall, New York.

ROUSH, R. T. AND HOY, M. A. 1981. Laboratory, glasshouse and field studies of artificially selected carbaryl resistance in Metaseiulus occidentalis. J. Econ. Entomol., 74, 142-147. 
ROUSH, R. T. AND McKENZIE, J. A. 1987. Ecological genetics of insecticide and acaricide resistance. Annu. Rev. Entomol., 32, 361-380.

SMITH, P., BERDOY, M., SMITH, R. H. AND MACDONALD, D. W. 1993. A new aspect of warfarin resistance in wild rats: benefits in the absence of the poison. Functional Ecol., 7, 190-194.

SODERLUND, D. M. AND BLOOMQUIST, J. R. 1990. Molecular mechanisms of insecticide resistance. In: Roush, R. T. and
Tabashnik, B. E. (eds) Pesticide Resistance in Arthropods, pp. 58-96. Chapman and Hall, New York.

TAYLOR, C. E. AND GEORGHIOU, G. P. 1979. Suppression of insecticide resistance by alteration of gene dominance and migration. J. Econ. Entomol., 72, 105-109.

WOOD, R. J. AND BISHOP, J. A. 1981. Insecticide resistance: populations and evolution. In: Bishop, J. A. and Cook, L. M. (eds) Genetic Consequences of Man Made Change, pp. 97-127. Academic Press, New York. 